\title{
Genetic Parameters and Breeding for Yield in Red Raspberry
}

\author{
M. Joseph Stephens ${ }^{1}$, Peter A. Alspach, and Ron A. Beatson \\ The New Zealand Institute for Plant and Food Research Limited, Motueka Research Centre, 55 Old \\ Mill Road, Motueka 7198, New Zealand
}

Chris Winefield

Lincoln University, Faculty of Agriculture and Life Sciences, Lincoln University, P.O. Box 84, Lincoln

7647, Canterbury, New Zealand

\author{
Emily J. Buck \\ The New Zealand Institute for Plant and Food Research Limited, Batchelar Road, Private Bag 11600 , \\ Palmerston North, 4442 New Zealand
}

\begin{abstract}
AdDitional INDEX wORDs. breeding values, heritability, genetic correlation, phenotypic correlation
ABSTRACT. For most small fruit-breeding programs, high yield is a key objective and breeders face a number of challenges breeding for high yield, including interaction of environmental influences and the high cost of yield measurements. Red raspberry (Rubus idaeus) yield is determined by a number of yield components (YC), including cane number, cane length, number of fruiting laterals, fruit numbers, and fruit size. The ultimate goal for breeders would be to be able to select for high-yield genotypes using key YC as early in the life of the plant as possible. In this study we set out to determine how individual components of yield are inherited, determine which components contribute the most to total yield, and investigate whether it is possible using key components to make selections for high-yielding genotypes on 1- and 2-year-old plants. We estimated variance components, heritabilities, phenotypic and genotypic correlations, and breeding values for yield and YC from 1008 genotypes based on 85 families derived from 45 parents harvested over three seasons in Washington state. Narrow-sense heritability estimates varied from moderately low [0.2 for number of canes (NCAN)] to moderately high [0.69 for berry weight (BWT)]. In general, all YCs were positively correlated with total yield (TYLD). The highest genetic correlation with TYLD was found for BWT (0.8), followed by cane length (CLEN) (0.54) and number of fruit per lateral (NFRT) (0.5). NCAN had the lowest genetic correlation with TYLD (-0.03). Genotype $\times$ year $(\mathbf{G} \times Y)$ interaction was higher for some YCs than others. Berry weight, lateral length (LLEN), and NFRT were found to be the most stable overall seasons and the interaction was higher between the first and second years than between the second and third years of the study. To determine the most important YC, we calculated the correlations between the product of all combinations of subsets of the YC breeding values and TYLD. Berry weight, CLEN, and cane diameter (CDIA) were found to be the most important for 2009, 2010, and 2011, respectively. The two most important YCs were LLEN and BWT and this was consistent overall seasons. We demonstrate that it is possible to select high-yielding genotypes by measuring key components such as LLEN, CLEN, and BWT in the first and second fruiting seasons.
\end{abstract}

Genetic improvement for fruit yield remains a key breeding objective in raspberry breeding programs worldwide. Highyielding raspberry cultivars with good fruit quality characteristics and pest and disease resistance are most important in determining economic return to growers for both fresh and process markets. Over the period of crop domestication, breeders have increased yield significantly (Way et al., 1983), yet scope remains for further increases in crops such as raspberry, which have relatively short breeding histories (Jennings, 1988).

Stephens et al. (2009) outlined some of the difficulties breeders have with breeding for yield in raspberry. These include the interaction of genetic, cultural, and environmental influences on total yield and the time-consuming nature of yield measurements for individual plants and small plot trials. Floricane fruiting

Received for publication 27 Apr. 2012. Accepted for publication 29 May 2012. We thank Julie Enfield, Micah Blondeau, Lawrence Graham, and Donna Graham who helped to coordinate the harvest; David Stevenson and Dave Andersen for chemistry analyses; and Adam Enfield and Enfield Farms Inc. for field management.

${ }^{1}$ Corresponding author. E-mail: jo.stephens@plantandfood.co.nz. raspberry plants have a biennial growth habit and produce upright canes each growing season that typically produce fruiting laterals the next season after a period of dormancy. Thus, for raspberry, there are a number of quantitatively inherited key components that cumulatively make up total yield, including cane number, cane length, number of fruiting laterals, fruit numbers, and fruit size.

Although all yield components interact with environmental influences to produce total yield, from a breeding point of view, there are key components that are likely to be better correlated with yield and are more heritable. We found few examples in the literature on the study of heritability and correlation of yield components in perennial fruit crops. However, numerous studies found that in tomato (Solanum lycopersicum), yield was most strongly correlated with fruit numbers per plant and fruit weight and that these traits had high heritability estimates (Anjum et al., 2009; Arun et al., 2004; Ramana et al., 2007; Vyas et al., 2011).

In raspberry, Dale and Daubeny (1985) showed that high yield was closely related to high lateral numbers in Abbotsford, British Columbia, Canada, and thick canes in Invergowrie, Scotland. Several studies have shown that raspberry yield is highly positively correlated with fruit size (Cormack and 
Woodward, 1977; Dale, 1976; Dale and Daubeny, 1985; Sha et al., 2011) and this is probably the easiest component for which breeders can select. Stephens et al. (2009) reported narrow-sense heritability $\left(h^{2}\right)$ values for a number of key YCs for floricane fruiting raspberry, found they ranged from relatively low $(0.23)$ to relatively high $(0.82)$, and suggested that some components contributed more to total yield than others. They found that in New Zealand, using estimated breeding values, cane length $\left(h^{2}=0.27\right)$, budbreak $\left(h^{2}=0.23\right)$, berry weight $\left(h^{2}=\right.$ $0.82)$, and fruit number per lateral $\left(h^{2}=0.37\right)$ contributed the most to improvement in total yield.

These results suggest the easiest gain in total yield could come from breeders selecting for increased berry weight. The raspberry processing market in North America is currently made up of cultivars such as Meeker, Wakefield, and, historically, Willamette with relatively small fruit size (typically 3 to $3.5 \mathrm{~g}$ ). Large fruit (e.g., greater than $5 \mathrm{~g}$ ) are unlikely to be suited to some markets [e.g., those that require individually quick frozen (IQF) fruit], because a certain product size is desirable. This then creates a dilemma for breeders developing cultivars for the process market: how to increase fruit yield without necessarily increasing fruit size or using fruit size for selection for high yield.

The preferred strategy in breeding for yield would be to select individuals on the basis of key YC in the first and/or second fruiting season that reliably predict yield in the next years so that selections can be made within a shorter period, speeding up the breeding and selection process. Building on the work by Stephens et al. (2009), this study, conducted in Washington state, was set out to determine how individual YCs are inherited in this environment, analyze the effect of individual YCs on total fruit yield, determine which YCs have the greatest influence on total yield, and determine whether the YCs in the first fruiting seasons accurately predict total yield in later seasons. Parent material was floricane-fruiting and included selections originating from the Plant and Food Research, New Zealand-based breeding program, North American-bred cultivars, and breeding selections from the Plant and Food Research-Northwest Plant Co., Washington state-based raspberry breeding program.

\section{Materials and Methods}

An inheritance study, in the form of a double pairwise mating design, was set up in 2008 at Enfield Farms Inc. (lat. $48.935^{\circ} \mathrm{N}$, long. $122.542^{\circ} \mathrm{W}$ ), Lynden, Washington state, and analyzed over three growing seasons. The performance of the first "baby" crop in raspberry is not classed as indicative of mature plants; however, in this region under good agronomic management, first-year growth is such that the baby crop is often commercially harvested and sometimes can be evaluated for research purposes. By analyzing the $\mathrm{G} \times \mathrm{Y}$ interaction, we were able to determine how different the baby crop was than the second and third fruiting seasons from a breeding perspective.

Parental material. Controlled crosses were carried out in a double pairwise design involving 45 parents selected from the breeding program on the basis of phenotypic performance in preceding years. Parent selection was made as part of routine measurements by scoring key traits and total yield measurements. The double pairwise design should have resulted in 90 full-sib families with each parent being used in four crosses (twice as a female and twice as a male). However, failure of some crosses and poor seed germination meant there were only 85 families and a few instances where the reciprocal cross was used because the intended female parent had finished flowering before the intended male started.

Experimental Design. For the experimental design, the large number of families and interrelationships among these families was considered (Piepho and Williams, 2006) and an $\alpha$-design (Patterson and Williams, 1976) was adopted. The trial consisted of a randomized complete block design with two six-plant full-sib plots per family. There were two complete blocks, each with 12 subblocks of seven plots (i.e., 84 plots per block, which was sufficient because two of the 85 families had enough plants for only one plot). Plant spacing was $3 \mathrm{~m}$ between rows and $1 \mathrm{~m}$ between plants in rows, and normal agronomic practices were applied.

Each winter, spent floricanes were pruned out and all new canes tied into position and topped at $\approx 1.7 \mathrm{~m}$.

Plant measurements. All YC data were collected in the 2009, 2010, and 2011 seasons when the plants were (from field planting) 1, 2, and 3 years old, respectively. Time constraints prevented total fruit yield data being collected on all plants $(\mathrm{n}=1008)$.

Instead, for the first plant in each plot in $2009(\mathrm{n}=168)$ and for the first and second plants in 2010 and $2011(\mathrm{n}=336)$, TYLD (in grams) was measured by hand picking and weighing total fruit weight every $5 \mathrm{~d}$ throughout the season.

Before fruit ripening, the LLEN (in centimeters) and NFRT on six randomly chosen laterals from the upper, middle, and lower cane regions (i.e., two from each region) on all plants were measured. For berry weight, three times during the season (early, middle, and late), 30 berries were picked and taken to the laboratory, where B WT (in grams) was recorded.

In early fall (September), floricanes on all plants were pruned out and for each plant the NCAN, CLEN (in centimeters), and CDIA (in millimeters) of each cane were recorded. The number of buds and laterals per cane were recorded for a sample of three canes from each plant. Using these data, total number of buds/node (NBUD) and percent budbreak (PCBB) were calculated.

Statistical APproach. Analyses were performed using the mixed model (Lynch and Walsh, 1998):

$$
\mathbf{y}=\mathbf{X} \boldsymbol{\beta}+\mathbf{Z u}+\mathbf{e}
$$

where $\mathbf{y}$ is the vector of phenotypic values, $\boldsymbol{\beta}$ is the vector of fixed effects, $\mathbf{u}$ is the vector of random effects, $\mathbf{X}$ and $\mathbf{Z}$ are the incidence matrices relating the observations in $\mathbf{y}$ to the elements in $\boldsymbol{\beta}$ and $\mathbf{u}$, respectively, and $\mathbf{e}$ the vector of residuals. There were no fixed effects, other than the intercept, in the models we fitted. Genotypes (i.e., individual plants) were fitted as part of the random effects and considered to be normally distributed with mean 0 and variance-covariance matrix $G=\sigma_{A}^{2} A$, where $\sigma_{\mathrm{A}}^{2}$ is the additive genetic variance and $\mathbf{A}$ is the numerator relationship matrix (i.e., twice the coancestry matrix). The other random effects were block and subblock within block. The residuals, e, were considered to be normally distributed with mean 0 and variance $\mathbf{V}=\sigma^{2} \mathbf{I}$, where $\mathbf{I}$ is the identity matrix.

We used best linear unbiased predictors (BLUP) to determine the empirical breeding values (eBV) for individuals (Henderson, 1977):

$$
\hat{\mathrm{u}}=G Z^{\mathrm{T}} \mathrm{V}^{-1}(\mathrm{y}-\mathrm{X} \hat{\beta})
$$

The BLUP approach to estimating breeding values was originally developed for animal breeding and has not been used 
extensively in plant breeding. However, there are several recent examples of its application to perennial crops (Beatson et al., 2011; de Souza et al., 1998; Kouassi et al., 2009; Stephens et al., 2009; Tancred et al., 1995). Piepho et al. (2008) provide a description of the application of BLUP in plant breeding. Two key advantages of using the BLUP approach are that the predictors are better corrected for extraneous variation, and information from relatives can be incorporated using all pedigree information. Most raspberry cultivars share common ancestry (Dale et al., 1993) and in our study the mean coancestry between the parents was 0.11 , the maximum was 0.44 , and only $1.2 \%$ of the seedlings were completely unrelated.

Univariate, bivariate, and multivariate mixed models were fitted. The univariate models were used to obtain initial values for the bi- and multivariate models and to investigate potential spatial effects by fitting a first-order autocorrelation structure to both rows and plant position within row (Gilmour et al., 1997). Residual plots were examined to assess whether any data transformations were necessary and to control for the existence of outliers. For the bi- and multivariate models, trait was the only fixed effect. Experimental design (i.e., block and subblock) was included as random effects in all models except for $\mathrm{G} \times \mathrm{Y}$ models. The variance-covariance matrices were modeled such that estimates for all individual genetic variances and covariances were estimated for the genotype $\times$ trait interaction (i.e., unstructured), separate variances for each trait were estimated for block and subblock, but the covariances were assumed to be 0 , and the residual variance-covariance matrix was unstructured (i.e., as for genotype $\times$ trait). Variance components were estimated using data from all plants in the study for all traits except TYLD in which only the first (2009) or first and second (2010) plants were harvested.

For each trait, $\mathrm{G} \times \mathrm{Y}$ interactions were analyzed by fitting all pairwise bivariate models in which the set of observations for a trait within a season (i.e., 2009:2010, 2010:2011, 2009:2011) was taken to be a separate trait and a similar approach used to multivariate trait analysis. $\mathrm{G} \times \mathrm{Y}$ correlation, $\mathrm{r}_{\mathrm{G} \times \mathrm{Y}}$, SES were estimated using bootstrap. One thousand runs were done whereby for each run new data were constructed by adding the modeled residuals, sampled with replacement, to the fitted values. Each of these new data sets was analyzed to give 1000 estimates for $r_{\mathrm{G} \times \mathrm{Y}}$, and the SD of these provided an estimate of the $\mathrm{SE}$ of $\mathrm{r}_{\mathrm{G} \times \mathrm{Y}}$.

BLUP breeding values were obtained for the seedlings from the univariate analysis. Because the pedigree information was included, it was also possible to estimate the eBV for each parent. Narrow-sense heritability estimates, $h^{2}$, were calculated from the bivariate analysis as the ratio between the additive genetic variance and the sum of the residual variance and the additive genetic variance averaged overall estimates for that trait. Genotypic and phenotypic correlations were estimated from the additive genetic variance-covariance matrix of the bivariate analysis. SEs for the heritabilities were estimated using the Taylor series expansion (Dieters et al., 1995).

YIELD COMPONENT ANALYSIS. Before analysis, NFRT was converted to NFRT per centimeter of lateral and NBUD converted to NBUD per centimeter of cane, which enabled the product of all components to approximate total yield. We obtained breeding values from our multivariate model (eight YCs) using mean data from all 3 years. The correlation between the product of the eBV for the eight YC traits and mean TYLD of 2010 and 2011 seasons was calculated. In addition, correlations between TYLD and individual YC eBVs and the product of all possible combinations of six, five, four, three, and twoYC eBVs were calculated.

To determine if we could estimate total yield based on $\mathrm{YC}$ in early years, we correlated the eBV for YC measured in early years (2009 and 2010) with the eBV for total yield in later years (2010 and 2011). We tested four different weights for combining the 2009 and 2010 YC: 2009 YC only, mean of 2009 and $2010 \mathrm{YC}$, one quarter $2009 \mathrm{YC}$ plus three quarters $2010 \mathrm{YC}$, and 2010 YC only. For the mean and 2010 YC only, a single multivariate model was used to calculate the eBV, but for the other two combinations, the single multivariate model failed to converge and thus bivariate models were used. We used a crossvalidation approach whereby a random $80 \%$ (i.e., 268) of the harvested individuals was used to calculate the best one, two, or three YCs (i.e., those that correlated best with the TYLD eBV), and these YCs were then used to predict TYLD of the remaining $20 \%(n=68)$. The number of individuals that would need to be selected based on this prediction to find five of the top 10 yielders based on the actual TYLD eBV was computed for each combination. This entire process was repeated 1000 times.

All statistical analyses were conducting using R 2.12.0 (R Core Development Team, 2010) and the mixed models were fitted using the asreml-r package (Butler et al., 2006).

\section{Results}

Spatial effects were very small, as determined by the magnitude of the estimated correlations relative to their SES, the semivariograms, and the likelihood ratio test (data not shown) and were therefore not included in the final models. The residual plots indicated that the assumption of normality was tenable for all traits except for NCAN in 2009, for which a square-root transformation was used (data not shown).

Table 1 summarizes breeding values for parents in the pairwise study. The best parent for breeding for each trait can be selected from this table. For TYLD, NFRT, and BWT, the maximum parental eBVs were slightly more than double their minima (Table 1). In contrast, for CLEN, CDIA, and NBUD, the maximum parental eBVs were only $\approx 20 \%$ to $30 \%$ greater than their minima. In general, breeding selections had higher parental eBV for TYLD than cultivars. Thus, although there were 22 breeding selections among the 45 parents, nine of the top 10 and only two of the bottom 10 parents for TYLD were breeding selections.

Estimates for the narrow-sense heritability for TYLD and most YCs were consistent across the 3 years (Table 2). The ranges were mostly less than one SE, with the exceptions being CLEN, CDIA, and NBUD, for which the ranges were about one SE of the difference. In general, the heritability estimates were lowest for the first season (i.e., 2009). The notable exception to this was CLEN, which was expected given that canes are trimmed to length once the plants are well established. Only BWT had a mean heritability estimate greater than 0.5 , and LLEN had the highest estimate of the remaining traits.

Genotypic and phenotypic correlations ranged from negligible to highly negative or positive (Table 3 ). For TYLD, strong (i.e., greater than 0.5$)$ positive genetic correlations were found with BWT, CLEN, and NFRT, whereas those with NCAN and NBUD were negligible. Of particular interest are those pairs of traits for which the genetic correlation was considerably different from the phenotypic correlation (shown with a gray background in Table 3). In both of these cases, genetic correlations were stronger 
Table 1. Parent plant source and mean overall years of the parental empirical breeding values for total yield and yield components sorted from highest to lowest yield for parents of red raspberry pairwise study. ${ }^{z}$

\begin{tabular}{|c|c|c|c|c|c|c|c|c|c|c|}
\hline \multirow[b]{2}{*}{ Parent } & \multirow[b]{2}{*}{ Source ${ }^{y}$} & \multicolumn{9}{|c|}{ Yield components $^{\mathrm{x}}$} \\
\hline & & TYLD (g) & LLEN (cm) & NFRT (no.) & BWT (g) & NCAN (no.) & CLEN $(\mathrm{cm})$ & CDIA (mm) & NBUD (no.) & РCBB (\%) \\
\hline ZNK019 & $\mathrm{BS}$ & 3974 & 54.7 & 17.4 & 4.0 & 7.4 & 136.1 & 10.2 & 73.2 & 48.2 \\
\hline ZNK018 & BS & 3934 & 51.6 & 19.2 & 5.0 & 7.7 & 138.2 & 10.2 & 74.4 & 35.7 \\
\hline HR149 & $\mathrm{BS}$ & 3906 & 38.7 & 12.4 & 3.8 & 7.6 & 132.5 & 10.1 & 92.6 & 50.6 \\
\hline ZNK063 & $\mathrm{BS}$ & 3871 & 54.5 & 19.1 & 3.6 & 8.6 & 139.0 & 10.5 & 81.9 & 39.9 \\
\hline HR122 & $\mathrm{BS}$ & 3857 & 50.1 & 12.1 & 3.7 & 8.9 & 138.0 & 10.4 & 81.4 & 48.1 \\
\hline 'Tulameen' & SB & 3755 & 56.8 & 14.9 & 3.9 & 8.7 & 144.7 & 10.6 & 84.9 & 43.8 \\
\hline NR4 & $\mathrm{BS}$ & 3723 & 44.6 & 11.7 & 5.0 & 9.0 & 144.9 & 10.2 & 96.6 & 42.4 \\
\hline HR158 & $\mathrm{BS}$ & 3636 & 38.5 & 12.7 & 3.2 & 8.4 & 137.0 & 9.9 & 88.0 & 51.8 \\
\hline ZN05005 & BS & 3618 & 38.1 & 11.4 & 3.1 & 8.1 & 137.1 & 9.8 & 92.3 & 54.5 \\
\hline NR10 & BS & 3553 & 44.2 & 12.3 & 3.9 & 8.6 & 138.0 & 9.9 & 89.3 & 39.7 \\
\hline ZNK033 & BS & 3532 & 47.1 & 14.1 & 2.9 & 8.8 & 140.1 & 10.1 & 84.0 & 51.7 \\
\hline ZNJ042 & $\mathrm{BS}$ & 3509 & 46.5 & 11.0 & 4.2 & 9.2 & 141.3 & 10.4 & 87.1 & 47.5 \\
\hline ZN05012 & BS & 3497 & 47.2 & 16.1 & 3.6 & 7.4 & 137.3 & 10.3 & 90.9 & 54.8 \\
\hline ZNM001 & $\mathrm{BS}$ & 3497 & 47.6 & 15.4 & 2.9 & 10.1 & 141.0 & 9.8 & 87.0 & 42.1 \\
\hline NR3 & $\mathrm{BS}$ & 3492 & 42.5 & 15.3 & 4.2 & 7.8 & 139.7 & 11.1 & 98.9 & 49.7 \\
\hline 'Motueka' & PFR & 3485 & 40.0 & 16.3 & 3.6 & 8.2 & 143.8 & 11.2 & 100.9 & 44.3 \\
\hline ZN05022 & BS & 3441 & 52.3 & 18.5 & 3.4 & 9.5 & 146.5 & 10.8 & 96.3 & 36.9 \\
\hline 'Meeker' & NWP & 3424 & 54.6 & 14.4 & 3.6 & 11.3 & 145.4 & 9.7 & 77.3 & 39.6 \\
\hline 'Haida' & NF & 3380 & 37.4 & 13.5 & 2.9 & 10.4 & 134.2 & 9.6 & 93.1 & 45.4 \\
\hline 'Saanich' & NWP & 3371 & 44.9 & 16.9 & 3.6 & 6.6 & 138.3 & 10.6 & 99.8 & 39.6 \\
\hline NR9 & $\mathrm{BS}$ & 3261 & 44.5 & 15.7 & 4.0 & 9.2 & 140.9 & 10.5 & 93.1 & 40.6 \\
\hline HR104 & $\mathrm{BS}$ & 3212 & 45.6 & 15.2 & 3.6 & 8.8 & 138.4 & 10.6 & 91.3 & 47.0 \\
\hline 'Wakefield' & PFR & 3192 & 52.2 & 14.3 & 3.5 & 9.9 & 140.9 & 10.3 & 72.7 & 40.9 \\
\hline 'Cuthbert' & NCGR & 3186 & 53.2 & 15.0 & 3.0 & 11.4 & 145.9 & 10.4 & 75.9 & 42.5 \\
\hline 'Coho' & NCGR & 3182 & 45.1 & 13.0 & 3.7 & 11.5 & 141.0 & 9.5 & 79.7 & 38.1 \\
\hline 'Moutere' & PFR & 3174 & 42.1 & 9.5 & 3.4 & 9.9 & 135.5 & 9.9 & 84.1 & 50.8 \\
\hline 'Encore' & $\mathrm{NF}$ & 3157 & 47.2 & 10.4 & 3.8 & 10.7 & 135.6 & 10.1 & 72.2 & 46.4 \\
\hline NR12 & $\mathrm{BS}$ & 3046 & 43.2 & 9.8 & 3.4 & 10.6 & 144.0 & 9.7 & 88.3 & 33.4 \\
\hline 'Cowichan' & NWP & 3044 & 53.8 & 12.6 & 4.6 & 10.0 & 142.2 & 10.6 & 77.5 & 41.0 \\
\hline 'Nootka' & NCGR & 3000 & 52.5 & 15.4 & 2.3 & 9.2 & 139.4 & 9.5 & 84.4 & 39.2 \\
\hline 'Chilliwack' & NCGR & 2953 & 46.1 & 10.8 & 3.1 & 7.5 & 137.1 & 11.0 & 83.5 & 41.2 \\
\hline 'Willamette' & NWP & 2937 & 41.8 & 12.8 & 2.7 & 10.1 & 137.2 & 9.0 & 88.7 & 36.2 \\
\hline ZNM003 & BS & 2903 & 50.9 & 11.8 & 2.5 & 11.0 & 144.8 & 10.1 & 87.8 & 45.7 \\
\hline ‘Lauren’ & $\mathrm{NF}$ & 2865 & 53.3 & 12.1 & 4.2 & 8.8 & 139.2 & 9.9 & 79.5 & 24.9 \\
\hline ‘Titan’ & NF & 2860 & 45.0 & 11.7 & 4.6 & 8.4 & 137.2 & 10.4 & 90.9 & 42.1 \\
\hline ZN05015 & BS & 2795 & 51.1 & 15.7 & 2.9 & 10.0 & 139.2 & 9.6 & 76.2 & 49.1 \\
\hline 'Taylor' & NCGR & 2675 & 42.7 & 12.7 & 2.8 & 9.7 & 137.8 & 10.3 & 88.7 & 34.8 \\
\hline ZN05018 & BS & 2546 & 34.8 & 13.6 & 2.9 & 6.6 & 139.2 & 10.2 & 97.9 & 46.8 \\
\hline 'Killarney' & $\mathrm{NF}$ & 2488 & 38.1 & 9.9 & 3.8 & 7.7 & 130.4 & 10.1 & 80.6 & 47.4 \\
\hline ‘Vene’ & NCGR & 2384 & 51.4 & 15.0 & 2.8 & 8.2 & 140.3 & 9.8 & 92.0 & 41.3 \\
\hline 'Prelude' & NF & 2309 & 38.4 & 9.3 & 2.7 & 9.1 & 133.0 & 9.8 & 85.5 & 48.5 \\
\hline 'Boyne' & NF & 2305 & 39.3 & 10.4 & 2.6 & 8.4 & 131.5 & 10.2 & 96.2 & 44.3 \\
\hline 'Latham' & $\mathrm{NF}$ & 2137 & 37.6 & 10.0 & 2.7 & 7.9 & 129.1 & 9.9 & 89.4 & 42.5 \\
\hline 'Nova’' & NF & 2048 & 37.2 & 9.0 & 2.5 & 9.3 & 133.8 & 9.8 & 99.3 & 33.6 \\
\hline K81-6 & $\mathrm{NF}$ & 1944 & 37.0 & 12.3 & 2.8 & 9.1 & 131.8 & 9.6 & 85.3 & 43.6 \\
\hline Mean & & 3157 & 45.7 & 13.4 & 3.4 & 9.0 & 138.6 & 10.1 & 86.9 & 43.3 \\
\hline Mean SE & & 480.7 & 2.99 & 1.08 & 0.22 & 0.83 & 3.25 & 0.32 & 4.18 & 3.05 \\
\hline Minimum SE & & 365.3 & 2.51 & 0.90 & 0.20 & 0.66 & 2.49 & 0.26 & 3.55 & 2.56 \\
\hline Maximum SE & & 569.4 & 4.01 & 1.45 & 0.31 & 1.02 & 3.94 & 0.41 & 5.45 & 4.09 \\
\hline
\end{tabular}

${ }^{\mathrm{z}}$ Maximum values are indicated in bold and minima in italic.

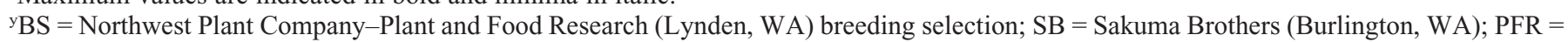
Plant and Food Research (Motueka, New Zealand); NWP = Northwest Plant Co. (Lynden, WA); NF = Nourse Farms (Whately, MA); NCGR = National Clonal Germplasm Respository (Corvallis, OR).

${ }^{x}$ TYLD $=$ total yield; LLEN = lateral length; NFRT = number of fruit per lateral; BWT = berry weight; $\mathrm{NCAN}=$ number of canes; CLEN = cane length; CDIA = cane diameter; NBUD = number of buds per cane; $\mathrm{PCBB}=$ percent budbreak. 
than phenotypic correlations. We found a strong negative genetic correlation between PCBB and CLEN, whereas the phenotypic correlation was only slightly negative. A positive genetic correlation was found between CLEN and NCAN, whereas the phenotypic correlation was weak. This suggests selection for long canes will result in higher NCAN and lower PCBB.

Genetic correlations between the years were high (i.e., $\mathrm{G} \times \mathrm{Y}$ interactions were low) for some traits (e.g., BWT, LLEN, and NFRT) but relatively low for others (e.g., CLEN, NCAN, and CDIA) (Table 4). CLEN had the lowest correlation between years and hence the highest $\mathrm{G} \times \mathrm{Y}$ interaction. The $\mathrm{G} \times \mathrm{Y}$ interactions were generally greater between 2009 and 2010 than between 2010 and 2011 and were generally greater still between 2009 and 2011.

Using mean data from all years, the correlation between the product of all eight YC eBVs and TYLD was 0.61 (data not shown). This correlation was improved by the best seven (excluding NBUD, $r=0.66$ ), the best six (additionally excluding CDIA, $r=0.68$ ), the best five (additionally excluding CLEN $r=$ 0.67 ), and reduced by the best four (additionally excluding NCAN $r=0.59$ ) and the best three (additionally excluding CLEN $r=0.56)$. Correlation of TYLD with the best product of two YCs was lower ( $r=0.50$ for product of LLEN and BWT), and the single best trait was CLEN $(r=0.45)$. When BWT was

Table 2. Narrow-sense heritability estimates $\left(h^{2}\right)$, and their SES, for each trait in each year and mean $h^{2}$ from all years from the red raspberry pairwise study.

\begin{tabular}{|c|c|c|c|c|c|c|c|}
\hline \multirow[b]{2}{*}{ Trait $^{z}$} & \multicolumn{2}{|c|}{2009} & \multicolumn{2}{|c|}{2010} & \multicolumn{2}{|c|}{2011} & \multirow[b]{2}{*}{ Mean $h^{2}$} \\
\hline & $h^{2}$ & SE & $h^{2}$ & SE & $h^{2}$ & SE & \\
\hline $\begin{array}{l}\text { TYLD } \\
\text { Ty }\end{array}$ & 0.24 & 0.172 & 0.20 & 0.103 & 0.32 & 0.150 & 0.25 \\
\hline LLEN & 0.38 & 0.137 & 0.50 & 0.170 & 0.44 & 0.151 & 0.44 \\
\hline NFRT & 0.30 & 0.109 & 0.47 & 0.162 & 0.39 & 0.130 & 0.39 \\
\hline BWT & 0.63 & 0.207 & 0.75 & 0.254 & 0.70 & 0.231 & 0.69 \\
\hline NCAN & 0.14 & 0.064 & 0.21 & 0.079 & 0.23 & 0.092 & 0.20 \\
\hline CLEN & 0.28 & 0.108 & 0.32 & 0.115 & 0.09 & 0.055 & 0.23 \\
\hline CDIA & 0.08 & 0.048 & 0.25 & 0.096 & 0.29 & 0.107 & 0.21 \\
\hline NBUD & 0.18 & 0.076 & 0.22 & 0.090 & 0.44 & 0.148 & 0.28 \\
\hline PCBB & 0.28 & 0.107 & 0.44 & 0.150 & 0.26 & 0.099 & 0.33 \\
\hline
\end{tabular}

${ }^{\mathrm{z} T Y L D}=$ total yield; LLEN $=$ lateral length; NFRT $=$ number of fruit per lateral; BWT = berry weight; $\mathrm{NCAN}=$ number of canes; $\mathrm{CLEN}=$ cane length; $\mathrm{CDIA}=$ cane diameter; $\mathrm{NBUD}=$ number of buds per cane; $\mathrm{PCBB}=$ percent budbreak. excluded from the analysis, the product of the best two YCs ( $r=$ $0.45)$ was for CLEN and CDIA and the best three $(r=0.49)$ was for CLEN, LLEN, and PCBB and all six YC $(r=0.43)$.

Using YC measured in the first and second year to predict mean yield in the second and third year, our analysis showed some influence of year on the single most important YC with BWT the single most important in 2009, CLEN the most important for combinations of 2009 and 2010 data, and CDIA in 2010 (Table 5). The best pair of YCs was LLEN and BWT irrespective of year, and the product of these two was nearly as well correlated with TYLD as the best three YCs. Based on our crossvalidations, the combination of one quarter 2009 data and three quarters 2010 data for LLEN and BWT provided the best opportunity for selecting for high-yielding genotypes with the lowest number of genotypes needing to be retained to select at least five of the top 10 yielding genotypes (Table 5). In general, the number of genotypes needed to be selected to ensure selection of five of the top 10 yielders based on top one, two, or three YC combinations was lower when we included 2010 data (Table 5).

\section{Discussion}

Narrow-sense heritability estimates were mostly consistent with those reported by Stephens et al. (2009) on a raspberry population in New Zealand with the exception of NCAN, for which they reported 0.64 (compare with 0.20 in the current study) and perhaps NBUD (0.46 compared with 0.28$)$. In particular, the heritability estimates for BWT (0.82 compared with 0.69$)$, LLEN (0.31 compared with 0.44$)$, and TYLD (0.24 compared with 0.25$)$ were similar between the two studies. Total yield is renowned for low heritability in crops and BWT has been previously reported with high heritability (Dale, 1989; Fejer, 1977; Sha et al., 2011). It is postulated that the reason for the higher heritability values in 2010 and 2011 compared with 2009 relates to the physiological age of the plants. In their first year, raspberry seedling plants grown from plugs grow fewer, fatter canes that tend to branch more than older plants, which influences CDIA and NCAN, resulting in a higher GXY interaction between first and second years.

This is likely to be the reason why $\mathrm{G} \times \mathrm{Y}$ interactions were higher between 2009 and 2010. Although the baby crop on raspberries can be economic to harvest, plant behavior is different from that in following years. For 2009 data, we were unable to achieve multivariate model convergence including CDIA, and the young age of the plants may explain this.

Table 3. Genetic (bottom triangle) and phenotypic (upper triangle) correlations, averaged over the 3 years, for all pairs of traits from red raspberry pairwise study. ${ }^{\mathrm{z}}$

\begin{tabular}{lrrrrrrrrr}
\hline Trait $^{y}$ & TYLD & LLEN & NFRT & BWT & NCAN & CLEN & CDIA & NBUD & PCBB \\
\hline TYLD & & $\mathbf{0 . 5 4}$ & 0.43 & $\mathbf{0 . 5 6}$ & 0.31 & 0.36 & 0.28 & -0.06 & 0.14 \\
LLEN & 0.28 & & 0.58 & 0.32 & 0.32 & 0.40 & 0.22 & -0.28 & -0.02 \\
NFRT & $\mathbf{0 . 5 0}$ & 0.51 & & 0.17 & 0.04 & 0.21 & 0.19 & -0.06 \\
BWT & $\mathbf{0 . 8 0}$ & 0.16 & 0.09 & & 0.02 & 0.16 & 0.18 & -0.09 & -0.00 \\
NCAN & -0.03 & 0.25 & -0.13 & -0.15 & & 0.12 & -0.15 & -0.13 & -0.18 \\
CLEN & $\mathbf{0 . 5 4}$ & 0.63 & 0.18 & 0.21 & 0.63 & & 0.44 & 0.18 \\
CDIA & 0.30 & 0.21 & 0.36 & 0.34 & -0.06 & 0.22 & -0.07 \\
NBUD & 0.06 & -0.53 & -0.02 & -0.11 & -0.23 & -0.04 & 0.27 & 0.10 \\
PCBB & 0.20 & -0.29 & -0.12 & -0.10 & -0.35 & -0.48 & -0.05 & 0.03 \\
\hline
\end{tabular}

${ }^{\mathrm{z}}$ Correlations with total yield (TYLD), which are greater than 0.5 , are marked in bold, and pairs for which the magnitude of the difference between the genetic and phenotypic correlations is large (arbitrarily defined as greater than 0.4 ) are shown with a gray background.

${ }^{y}$ LLEN = lateral length; NFRT = number of fruit per lateral; BWT = berry weight; NCAN = number of canes; CLEN = cane length; CDIA = cane diameter; NBUD = number of buds per cane; PCBB = percent budbreak. 
We found similar genetic correlations between TYLD and YC to Stephens et al. (2009), who measured the same YC (except for CDIA) in red raspberry in New Zealand during a single season. Their study found the highest genetic correlations with TYLD for BWT (0.53) CLEN (0.49), and LLEN (0.38), whereas in Washington, BWT (0.80), CLEN (0.54), and NFRT $(0.50)$ were the highest. These correlations suggest selection for these traits will aid selection for higher yield. Many genes contribute to TYLD and it is likely that the genetic correlations we have observed between TYLD and its components are a result of pleiotropy and linked genes. For traits with high heritabilities such as BWT, the phenotypic correlations are driven by genetic factors rather than environmental factors, whereas for traits with low heritabilities such as CDIA, the phenotypic correlations are driven by environmental factors.

Table 4. Genotype $\times$ year correlations $\left(r_{G Y}\right)$, and their SES, for each trait between all year pairs from the red raspberry pairwise study.

\begin{tabular}{lcccccccc}
\hline & \multicolumn{2}{c}{$2009: 2010$} & & \multicolumn{2}{c}{$2010: 2011$} & & \multicolumn{2}{c}{$2009: 2011$} \\
\cline { 2 - 3 } Trait $^{z}$ & $\mathrm{r}_{\mathrm{GY}}$ & $\mathrm{SE}$ & & $\mathrm{r}_{\mathrm{GY}}$ & $\mathrm{SE}$ & & $\mathrm{r}_{\mathrm{GY}}$ & $\mathrm{SE}$ \\
\hline TYLD & 0.97 & 0.304 & & 0.56 & 0.247 & & 0.87 & 0.289 \\
LLEN & 0.87 & 0.048 & & 0.89 & 0.036 & & 0.88 & 0.041 \\
NFRT & 0.82 & 0.056 & & 0.85 & 0.042 & & 0.78 & 0.063 \\
BWT & 0.96 & 0.009 & & 0.98 & 0.006 & & 0.96 & 0.011 \\
NCAN & 0.44 & 0.436 & & 0.83 & 0.167 & & 0.30 & 0.423 \\
CLEN & 0.15 & 0.143 & & 0.68 & 0.176 & & -0.50 & 0.197 \\
CDIA & 0.45 & 0.178 & & 0.58 & 0.124 & & 0.56 & 0.169 \\
NBUD & 0.84 & 0.051 & & 0.86 & 0.046 & & 0.36 & 0.098 \\
PCBB & 0.77 & 0.054 & & 0.93 & 0.033 & & 0.67 & 0.081
\end{tabular}

${ }^{\mathrm{z} T Y L D}=$ total yield; LLEN $=$ lateral length; NFRT $=$ number of fruit per lateral; BWT = berry weight; $\mathrm{NCAN}=$ number of canes; $\mathrm{CLEN}=$ cane length; CDIA = cane diameter; NBUD = number of buds per cane; $\mathrm{PCBB}=$ percent budbreak.
The strong influence of CDIA in 2010 was also reflected in a high genetic correlation of CDIA with TYLD for 2010 $(r=0.83$, data not shown). We only observed this result for the 2010 season and not in $2009(r=0.07)$ and $2011(r=0.01)$. The phenotypic correlation of CDIA and TYLD in 2010 was significantly less (0.4) and the low heritability of CDIA suggests this correlation was driven by environmental factors. However, our 2010 result is consistent with the studies of Dale and Daubeny (1985) who found that high yield was associated with thick canes in Scotland. Coinciding with the high genetic correlation of CDIA with TYLD in 2010 was high correlation of CLEN with TYLD and a significantly lower genetic correlation of PCBB with TYLD compared with that in 2009 and 2011. Also, we found strong negative correlations between CLEN and PCBB in 2010 and 2011. Some commercially grown raspberry plant canes (including those in our study) are pruned just above the top wire at a height of $\approx 1.7 \mathrm{~m}$ and thus in our study, longer canes are more likely to be pruned. Shorter canes that do not reach the top wire are not pruned and from our results appear to have higher PCBB, probably because the terminal buds (which may be more likely to break) are not removed. In years when CLEN is important as a component influencing yield (particularly the first and second), high PCBB appears less important in influencing yield. It is likely that yearly changes in environmental conditions interact with genetic control of $\mathrm{YC}$ to alter which components are most influential between seasons. It maybe that in seasons that favor strong cane growth, CLEN and CDIA are more important for influencing yield than $\mathrm{PCBB}$, whereas in seasons that promote less cane growth, PCBB becomes more important. In our study CLEN, PCBB, and CDIA were among YCs with the highest $\mathrm{G} \times \mathrm{Y}$ interaction.

In general, YCs associated with fruiting laterals and berries (i.e., LLEN, NFRT, and BWT) had higher genetic correlations with TYLD than those associated with canes (i.e., NCAN, CLEN, CDIA, NBUD, and PCBB). The exception was CLEN, which had a correlation similar to that for NFRT. This was also

Table 5. The top-ranked simulated yield component, the percentage of iterations (of 1000) for which the component(s) was top, the mean correlation of the component (or sum of components) breeding value with mean 2010 and 2011 total yield, and the number of individuals that would need to be selected based on top-ranked components to ensure five of the actual top 10 yielders were retained from a red raspberry pairwise study.

\begin{tabular}{llccc}
\hline Yield components & \multicolumn{1}{c}{ Data } & $\begin{array}{c}\text { Iterations component } \\
\text { top }(\%)^{\mathrm{y}}\end{array}$ & $\begin{array}{c}\text { Mean correlation } \\
\text { with total yield }\end{array}$ & $\begin{array}{c}\text { Genotypes to select to include 5 } \\
\text { of top 10 yielders (no.) }\end{array}$ \\
\hline BWT & 2009 & 57 & 0.44 & 26 \\
CLEN & $2009: 2010^{\mathrm{w}}$ & 81 & 0.45 & 33 \\
CLEN & $2009: 2010^{\mathrm{v}}$ & 56 & 0.46 & 30 \\
CDIA & 2010 & 100 & 0.47 & 21 \\
LLEN:BWT & 2009 & 100 & 0.52 & 26 \\
LLEN:BWT & $2009: 2010^{\mathrm{y}}$ & 94 & 0.52 & 21 \\
LLEN:BWT & $2009: 2010^{\mathrm{x}}$ & 100 & 0.55 & 19 \\
LLEN:BWT & 2010 & 100 & 0.50 & 20 \\
PCBB:LLEN:BWT & 2009 & 52 & 0.53 & 25 \\
PCBB:LLEN:BWT & $2009: 2010^{\mathrm{y}}$ & 99 & 0.58 & 21 \\
PCBB:LLEN:BWT & $2009: 2010^{\mathrm{x}}$ & 50 & 0.57 & 22 \\
NCAN:NFRT:BWT & 2010 & 52 & 0.53 & 24 \\
\hline
\end{tabular}

${ }^{\mathrm{z}} \mathrm{LLEN}=$ lateral length; NFRT $=$ number of fruit per centimeter of lateral; BWT = berry weight; NCAN = number of canes; $\mathrm{CLEN}=$ cane length; $\mathrm{CDIA}=$ cane diameter; $\mathrm{PCBB}=$ percent budbreak.

${ }^{\mathrm{y}} \mathrm{For} 80 \%$ of the population.

${ }^{x}$ For the remaining $20 \%$ of the population.

${ }^{\text {w}}$ Mean of 2009 and 2010 yield components.

${ }^{v}$ Weighted mean using 0.25 (2009) and 0.75 (2010) yield components. 
reflected in the ability of the YC to predict TYLD. We also found heritability estimates of traits associated with laterals and berry weight were higher and $\mathrm{G} \times \mathrm{Y}$ interactions lower than those for other YC traits.

From our results, there appears to be benefit in evaluating both the first and second fruiting seasons because there is greater $\mathrm{G} \times \mathrm{Y}$ interaction between the first (baby crop) and second season than between the second and third season, and according to our simulations, the number of genotypes that need to be selected to retain top yielders is lower when first and second season data are included.

In our study, BWT and LLEN were consistently the best two YC correlating with TYLD, which is consistent with the results of Stephens et al. (2009) who found the best YC correlations with TYLD, excluding $R$. Parv derivative, were BWT, CLEN, and LLEN. In terms of practical application to a breeding program, LLEN, CLEN, and BWT are relatively quick and easy to measure as proxies for total yield. Although BWT had the highest genetic correlation with TYLD and was a major influencing component contributing to TYLD, we have shown that LLEN and CLEN also are important YC in breeding for high yield. It should be noted, however, that breeding for longer fruiting laterals should be regarded in context with machine harvesting. Breeders need to be sure that longer laterals are not too long to enable the machine to pass and strong enough to not break. To avoid berries becoming too large for process markets, breeders may place less emphasis on BWT and more on LLEN and CLEN; however, the importance of BWT cannot be ignored and it is likely that there is potential to further increase berry size for process markets before they are considered too large. Genetic gain will be good, because these traits have (with the exception of CLEN) high heritabilities and (with the exception of LLEN), high genetic correlations with total yield, and low $\mathrm{G} \times \mathrm{Y}$ interaction. Selection for high yielders could thus be made by measuring BWT, LLEN, and CLEN in the first and/ or second season and then using these data to decide which plants to harvest in the second and/or third season.

Our study has shown that, in the Washington state environment, all YCs we measured contribute to TYLD; however, BWT, LLEN, and CLEN consistently had the greatest influence on TYLD over several years. Thus, to reduce the time and effort in measuring TYLD in seedling populations, a breeder could use these traits in the first and second fruiting years to reduce the number of seedlings from which TYLD and other data are measured in proceeding years.

\section{Literature Cited}

Anjum, A., N. Raj, A. Nazeer, and S.H. Khan. 2009. Genetic variability and selection parameters for yield and quality attributes in tomato. Indian J. Hort. 66:73-78.

Arun, J., V. Amit, and M.C. Thakur. 2004. Studies on genetic variability, correlation and path analysis for yield and physicochemical traits in tomato (Lycopersicon esculentum Mill.). Prog. Hort. 36:51-58.

Beatson, R.A., P.A. Alspach, A.J. Currie, P.M. Harris-Virgin, and A. White. 2011. Genetic parameters for fruit traits of interspecific Actinidia hybrids. Acta Hort. 913:89-96.

Butler, D.G., B.R. Cullis, A.R. Gilmour, and B.J. Gogel. 2006. ASReml-R reference manual, release 2. Queensland Department of Primary Industries and Fisheries, Brisbane, Australia.

Cormack, M.R. and P.J. Woodward. 1977. Raspberry cultivar assessments at the national fruit trials and the Scottish Horticultural Research Institute. Expt. Hort. 29:1-14.
Dale, A. 1976. Prospects for breeding higher yielding raspberries. Acta Hort. 60:159-167.

Dale, A. 1989. Productivity in red raspberries. Hort. Rev. 11:185-227.

Dale, A. and H.A. Daubeny. 1985. Genotype-environment interactions involving British and Pacific Northwest red raspberry cultivars. HortScience 20:68-69.

Dale, A., P.P. Moore, R.J. McNicol, T.M. Sjulin, and L.A. Burmistrov. 1993. Genetic diversity of red raspberry varieties throughout the world. J. Amer. Soc. Hort. Sci. 118:119-129.

de Souza, V.A.B., D.H. Byrne, and J.F. Taylor. 1998. Heritability, genetic and phenotypic correlations, and predicted selection response of quantitative traits in peach: I. An analysis of several reproductive traits. J. Amer. Soc. Hort. Sci. 123:598-603.

Dieters, M.J., T.L. White, R.C. Littell, and G.R. Hedge. 1995. Application of approximate variances of variance-components and their ratios in genetic tests. Theor. Appl. Genet. 91:15-24.

Fejer, S.O. 1977. Inheritance of yield, yield components, and fallfruiting habit in red raspberry diallel crosses. Can. J. Genet. Cytol. 19:1-13.

Gilmour, A.R., B.R. Cullis, and A.P. Verbyla. 1997. Accounting for natural and extraneous variation in the analysis of field experiments. J. Agr. Biol. Environ. Stat. 2:269-293.

Henderson, C.R. 1977. Best linear unbiased estimation and prediction under a selection model. Biometrics 31:423-477.

Jennings, D.L. 1988. Raspberries and blackberries: Their breeding, diseases and growth. Academic Press, London, UK.

Kouassi, A.B., C.E. Durel, F. Costa, S. Tartarini, E. van de Weg, K. Evans, F. Fernandez-Fernandez, C. Govan, A. Boudichevskaja, F. Dunemann, A. Antofie, M. Lateur, M. Stankiewicz-Kosyl, A. Soska, K. Tomala, M. Lewandowski, K. Rutkovski, E. Zurawicz, W. Guerra, and F. Laurens. 2009. Estimation of genetic parameters and prediction of breeding values for apple fruit-quality traits using pedigreed plant material in Europe. Tree Genet. Genomes 5:659672.

Lynch, M. and B. Walsh. 1998. Estimation of breeding values, p. 745 778. In: Lynch, M. and B. Walsh (eds.). Genetics and analysis of quantitative traits. Sinauer Associates, Sunderland, MA.

Patterson, H.D. and E.R. Williams. 1976. A new class of resolvable incomplete block designs. Biometrika 63:83-92.

Piepho, H.P., J. Mohring, A.E. Melchinger, and A. Buchse. 2008. BLUP for phenotypic selection in plant breeding and variety testing. Euphytica 161:209-228.

Piepho, H.P. and E.R. Williams. 2006. A comparison of experimental designs for selection in breeding trials with nested treatment structure. Theor. Appl. Genet. 113:1505-1513.

R Core Development Team. 2010. R: A language and environment for statistical computing. R Foundation for Statistical Computing, Vienna, Austria. 1 Feb. 2011. <http://www.R-project.org>.

Ramana, C.V., V.G. Shankar, S.S. Kumar, and P.V. Rao. 2007. Trait interrelationship studies in tomato (Lycopersicon esculentum Mill.). Res. Crops 8:213-218.

Sha, S.F., J.C. Li, J. Wu, and S.L. Zhang. 2011. Changes in the organic acid content and related metabolic enzyme activities in developing 'Xinping' pear fruit. African J. Agr. Res. 6:35603567.

Stephens, M.J., J. Scalzo, P.A. Alspach, R.A. Beatson, and A.M. Connor. 2009. Genetic variation and covariation of yield and phytochemical traits in a red raspberry factorial study. J. Amer. Soc. Hort. Sci. 134:445-452.

Tancred, S.J., A.G. Zeppa, M. Cooper, and J.K. Stringer. 1995. Heritability and patterns of inheritance of the ripening date of apples. HortScience 30:325-328.

Vyas, M., A.K. Singh, V.K. Rai, and M. Ramanand. 2011. Genetic variability, correlation and path coefficient analysis of tomato (Lycopersicon esculentum Mill.). Environ. Ecol. 29:1076-1081.

Way, R.D., J.C. Sanford, and A.N. Lasko. 1983. Fruitfulness and productivity, p. 353-367. In: Janick, J. and J.N. Moore (eds.). Methods in fruit breeding. Purdue Univ. Press, West Lafayette, IN. 